\title{
Student evaluation of clickers in a dental pathology course
}

\author{
Carmen Llena ${ }^{1}$, Leopoldo Forner ${ }^{1}$, Roger Cueva ${ }^{2}$
}

${ }^{1}$ MD, DDS, PhD, Department of Stomatology. Universitat de València, C/ Gascó Oliag, 1. 46010 Valencia, Spain

${ }^{2}$ DDS, Department of Stomatology. Universitat de València, C/ Gascó Oliag, 1. 46010 Valencia, Spain

Correspondence:

Department of Stomatology

Universitat de València

C/ Gascó Oliag, 1

46010 Valencia, Spain

llena@uv.es

Received: 09/01/2015 Accepted: $15 / 03 / 2015$

Llena C, Forner L, Cueva R. Student evaluation of clickers in a dental pathology course. J Clin Exp Dent. 2015;7(3):e369-73.

http://www.medicinaoral.com/odo/volumenes/v7i3/jcedv7i3p369.pdf

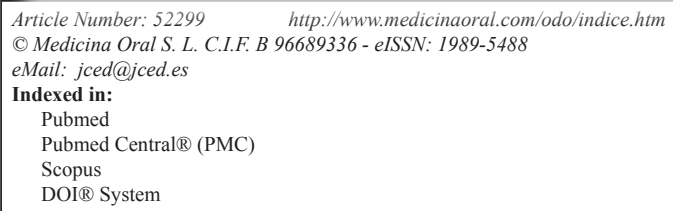

\begin{abstract}
Background: The purpose of this study was to evaluate the degree of satisfaction of students and teachers, and to determine whether the students notice improvements in learning and in the learning environment as a result of the use of clicker.

Material and Methods: Descriptive study. Fifty-one students and 8 teachers participated in the use of clicker technology in 8 preclinical seminars in dental pathology. Students and teachers filled a three-domain questionnaire at the end of the preclinical course. We used the Mann-Whitney U-test to compare the results between the two groups.

Results: The domain "perception and expectation" showed the use of clickers to be simple and convenient for $80 \%$ of the students, who expressed interest in extending the practice to other teaching areas. In the domain "active learning", over $70 \%$ of the students found the technique to be dynamic, participative and motivating. In the domain "improved learning", over 70\% considered it useful to know their level of knowledge before the seminar and found the contents of the lesson to be clear. Thirty percent considered the items of the examination to be of a complexity similar to that of the first and second tests. Only in this latter aspect were significant differences found between the teachers and students $(p=0.001)$.

Conclusions: Participants described the use of clickers as simple and useful, motivating and participative. Both the students and teachers considered the technique to improve teaching and the learning environment.
\end{abstract}

Key words: Dental education, audience response system, clickers, classroom response system, student's perception.

\section{Introduction}

The assessment of learning outcomes is the subject of research in teaching and involves the most objective evaluation possible of the competencies acquired by the student in the learning process (1).

Learning represents a genuine change in the knowledge, skills and attitudes of the students. The elements that conform the learning outcomes are difficult to define and even more difficult to evaluate. Consequently, specific objectives must be established in different settings, in relation to motor skills and the cognitive sphere (skills, attitudes, competencies), in the meta-cognitive domain (self-evaluation), and in the administrative area of the learning process (time spent, cost/efficacy, flexibility, etc.). Achieving these objectives results in satisfactory learning and therefore in a positive learning outcome. In this respect, the new technologies can be of help in reaching these objectives in all areas of the process (2).

Active learning requires a change in the educational paradigm, centering on the student and improving the interaction between students and teachers (3). The new technologies facilitates such interaction and, in general, 
are well accepted by the students and contribute to increase their motivation (4).

Classroom Response System (CRS) is a recently introduced educational tool. This technology allows students to respond and obtain feedback through an immediate response system referred to as the "clicker" method. These new systems are currently available on the market, involve very compatible software, are relatively inexpensive, and are easy to use $(5,6)$.

The simplification afforded by the clicker system is an important asset for use in the educational setting. Two types of system are presently available, respectively based on radiofrequency and infrared communication. The former are more indicated for use in large groups, since they are less vulnerable to interferences (7).

A number of authors suggest that these systems have great potential for improving student learning in the classroom, ensuring more active participation $(8,9)$. They allow evaluation during the class, improve attention, increase interaction, create a dynamic atmosphere, and add an enriching environment to communication $(5,10,11)$.

Some authors report the use of clickers in different educational areas, both in and outside the university setting $(12,13)$, and in dental schools too (14-20).

We introduced the clicker system in the third year of the Dental School of the University of Valencia (Valencia, Spain) for the teaching of dental pathology (DP). The aims of the present study are to describe our experience, evaluate the degree of satisfaction of students and teachers, and to determine whether the students notice improvements in learning and in the learning environment as a result of the use of this new technology.

\section{Material and Methods}

The present study used a questionnaire to explore the opinion of dental students and teachers in the University of Valencia on the use of clicker technology in preclinical seminars in dental pathology (DP). It was approved by the ethics committee of the University of Valencia (H1392830490155).

Dental Pathology (DP) forms part of the subject Dental Pathology, Operative Dentistry and Endodontics. The teaching of DP, in the third year of the Dental School, comprises a series of theoretical classes, preclinical seminars, and clinical practices. The present study was carried out in the context of the preclinical seminars, which number 8 in total and include the presentation of clinical, radiological and histological images referred to DP. These seminars were always programmed for after the theoretical classes. In each seminar the students received a guide detailing the most important aspects addressed in the seminar, together with literature sources for consultation purposes.

The study comprised a total of 51 students (all students enrolled in the subject of Dental Pathology) distributed into three groups of 17 students each, and 8 teachers. A teacher, familiarized with the Classroom Response System (CRS) and trained in the use of the specific clickers employed, imparted each seminar, on different days for each group of students; so, we prepared different groups of questions for each group. A single teacher prepared each of the 8 seminars. All the teachers reviewed and discussed the tests together for each of the seminars in order to ensure uniform presentation and complexity.

The first group of questions in each seminar consisted of 10 multiple choice questions prepared for answering with a radiofrequency clicker system (EduClick, NY, USA). Each of the questions had 5 possible answers, of which only one was correct. The questions could involve text or images and text. The students had 45 seconds to answer each of the questions.

Students filled the complete test at the start of the seminar. We performed an immediate checking of the number of right answers for each question, on an anonymous basis. Students and teacher discussed the different answering options for each question in a participative manner, as well as other images, similar to those presented in the test, shown by the teacher. We repeated the same group of questions to be answered with the clicker system, so the students could check the evolution of their group in terms of the number or right answers, on an anonymous basis. We analyzed questions correctly answered by less than $70 \%$ of the participants upon repeating the test again. Lastly, we performed an evaluative examination, comprising 15 questions similar to those dealt with during the seminar, using the clicker system. We used this exam to assess learning of the seminar. Figure 1 shows some examples of the questions in the tests.

After completion of the 8 seminars, an 11-item questionnaire evaluated the opinion of the students and teachers regarding the use of the clicker technology and its possible contribution to improved learning. In selecting these 11 items, and following an exhaustive literature review, we established three domains relating to the aspects we wished to explore: 1) "perception and expectation"; 2)

What is shown in the second right mandibular molar:

a) An underlying dark shadow

b) A localized enamel breackdown. Code 3 (ICDAS II index)

c) An old restoration.

d) A caries lesion. Code 4 (ICDAS II index)

e) Code 5 (ICDAS II index)

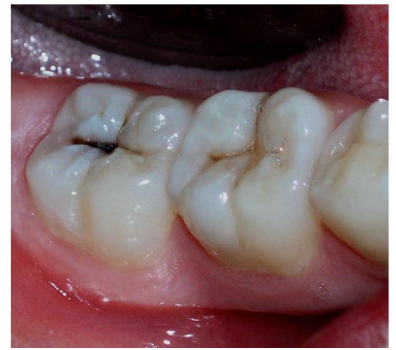

Fig. 1. Example of a question test. 
"active learning"; and 3) "improved learning". Then, we evaluated, in a session with all the participating teachers, different items corresponding to each domain for final inclusion in the questionnaire according to the relevance of the contents, simplicity and clarity (Table 1).

A Likert scale, from 1 (strongly disagree) to 5 (strongly agree), scored each item. A score of 3 represented "no opinion".

We evaluated internal reliability by Cronbach's alfa coefficient. We analyzed descriptive data referred to each of the proposed items and we used the Mann-Whitney U-test to compare differences between the students and teachers for each of the items, considering statistical significance for $p<0.05$.

\section{Results}

The questionnaire response rate among the students was 98.03\% (50/51). Eighty-six percent of the participants were females. The mean age of the students was $21.54 \pm$ 4.03 (range 20-37). Reliability, assessed by Cronbach's alpha coefficient, was 0.887 . The reliability of the three domains was 0.773 for "perception and expectation", 0.860 for "active learning" and 0.787 for "improved learning".

All of the teachers answered the questionnaire: two of them were full-time professors and the other 6 were associate lecturers. Their mean age was $44 \pm 10.02$ (range 30-55). Reliability, assessed by Cronbach's alpha, coefficient was 0.915 . The reliability of the three domains

Table 1. Descriptive analysis of students' and teacher's perceptions for each domain tested.

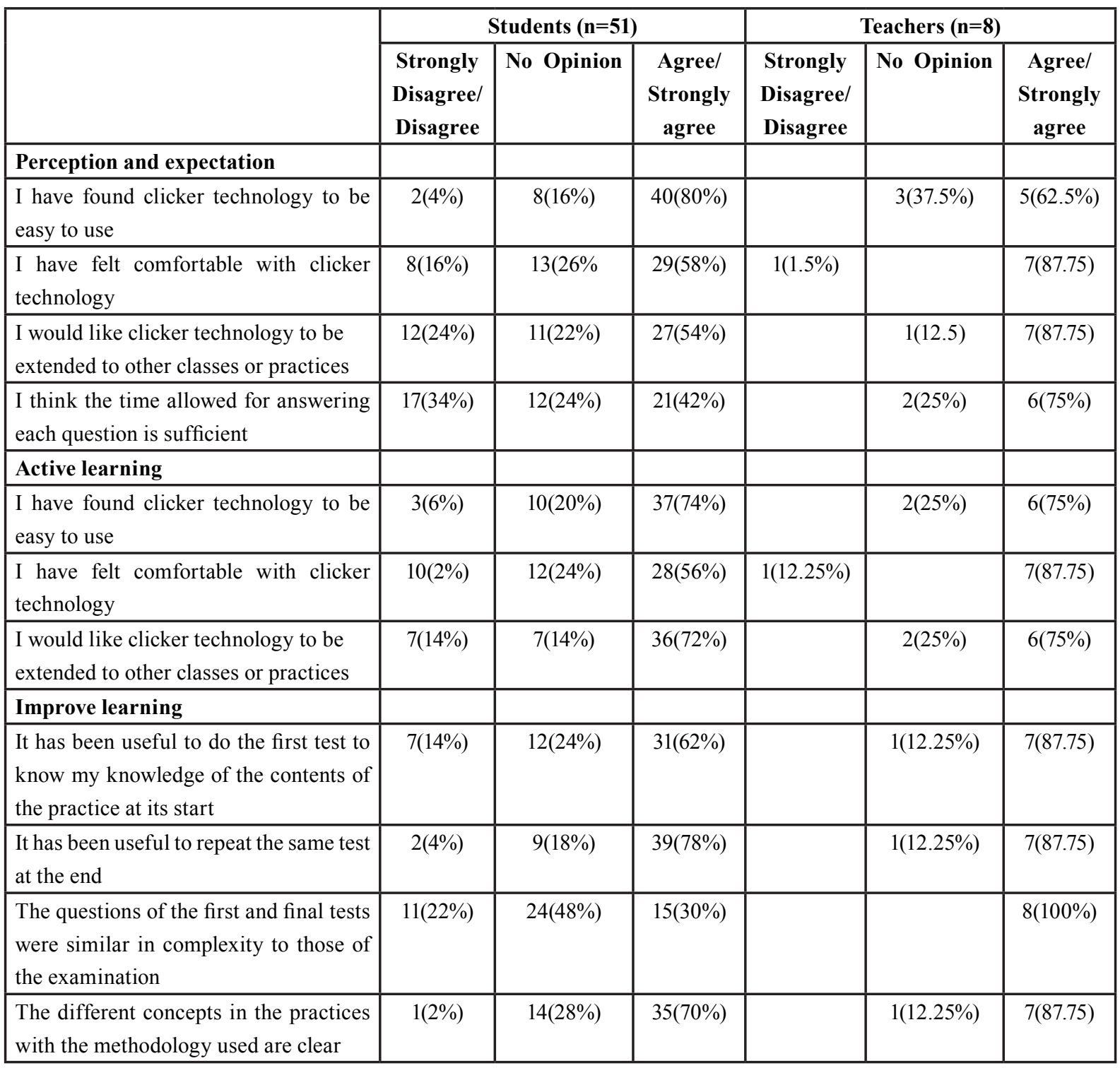


was 0.884 for "perception and expectation", 0.873 for "active learning" and 0.891 for "improved learning". Table 1 shows the descriptive results referred to each of the three domains among the students and teachers. For students, the domain "perception and expectation" showed the use of clickers to be simple and convenient for $80 \%$ of the students, who expressed interest in extending the practice to other teaching areas. In the domain "active learning", over $70 \%$ of the students found the technique to be dynamic, participative and motivating. Lastly, in the domain "improved learning", over $70 \%$ considered it useful to know their level of knowledge before the seminar and found the contents of the lesson to be clear. However, only $30 \%$ considered the items of the examination to be of a complexity similar to that of the first and second tests, while $48 \%$ had no opinion in this respect.

For teachers, the domain "perception and expectation" showed the use of clickers to be simple and convenient for $62.5 \%$ of the teachers, who likewise expressed interest in extending the practice to other teaching areas ( $87.5 \%$ of the teachers). In the domain "active learning", $75 \%$ of the teachers found the technique to be dynamic and participative, and $87.5 \%$ considered it to be motivating for learning. Lastly, in the domain "improved learning", $87.5 \%$ considered it useful to perform the first and second tests, and the concepts were considered to have been sufficiently clear. All of the teachers considered the items of the first and second tests to be of a complexity similar to that of the evaluative examination.

The Mann-Whitney U-test only identified significant differences between the teachers and the students in relation to item 10, which assessed similarity of complexity between the first and second tests and the evaluative examination $(p=0.07)$.

\section{Discussion}

Learning in dental pathology requires the evaluation of a series of clinical images allowing the student to identify the specific characteristics of the different lesions, with a view to consolidating knowledge and acquiring diagnostic skills. In this respect, seminars involving small groups of students are essential, since they allow the presentation of many images and discussion of the differentiating characteristics of the lesions with other students and with the teachers, before moving on to the clinical practices. The study of dental pathology requires good knowledge of dental anatomy, which is taught in the first year in Dental School. We imparted two introductory seminars to remind the students of dental crown and root morphology.

The introduction of interactive systems in teaching facilitates student attention, and increases curiosity and interaction between the students and teachers (21). It also helps relate new concepts to already acquired knowledge, thereby contributing to reflective learning (22).
We considered reliability, evaluated with Cronbach's alpha coefficient, to be acceptable for both the global test and for each of the domains, in both the teachers and students, and we considered a coefficient of at least 0.70 to be sufficient for an instrument in its early development stages.

Seventy-four percent of the students found the use of the clickers system to be dynamic, $72 \%$ considered it to be a participative procedure, and $60 \%$ found the technology to be motivating. These results are consistent with those of other authors (14) in relation to the teaching of periodontics and dental hygiene. Similar findings have also been published in the teaching of pediatric dental care (18).

The capacity to retain information is low in teaching methods in which the student remains passive in class (23). In the case of dental pathology, where the cognitive dimension predominates, the use of instruments designed to improve attention and inter-relate knowledge seems essential in order to improve learning.

Elashvili et al. (16) compared two groups, one involving interactive teaching and the other using conventional techniques for learning of the items "principles of dental bonding" and "class IV and V composite resin restorations". We recorded an increased retention capacity referred to "principles of dental bonding" in the interactive teaching group both at the end of the class and in transferring the knowledge to the practical setting. The students expressed a preference for the interactive system, which they considered to be more effective for understanding the concepts, maintaining attention, and retaining the information. Although our study did not compare two teaching systems in dental pathology, the students were well familiarized with the conventional teaching techniques used in the rest of the academic subjects and produced results similar to those of the mentioned study (16). The use of new technologies should also focus on the affective dimension of the teaching/learning process, which can contribute to increase interest and improve learning (12).

Teacher assessment of the clicker system largely coincided with that of the students. The only exception in this respect corresponded to the item: "The questions of the first and final (the evaluative one) tests were of a complexity similar to that of the examination", where all of the teachers considered complexity to be similar versus only $30 \%$ of the students. On the other hand, $48 \%$ of the students claimed to have no opinion in this respect. We founded no studies comparing teacher and student opinion referred to clicker systems, though this probably can be explained by different levels of experience in diagnosis.

The teachers, who had imparted seminars in dental pathology in the past, using conventional methods (i.e., without the clicker system), found the students to be more 
attentive during the seminars with the new system, more participative, and better able to consolidate knowledge. Indeed, in subsequent seminars that made use of concepts taught in previous seminars, the students showed greater knowledge and did not repeatedly ask the same questions.

The students found clickers useful to perform a first test in the seminar to know their level of knowledge, followed by a repetition of the test at the end. They also considered the concepts of the seminar to be clear with the use of the clicker system.

The use of clicker technology in the teaching of dental pathology is simple and useful, and should be extended to other subjects as well. In view of the results obtained, it would be advisable to extend this study and perform follow-up evaluations over coming academic courses.

\section{Conclusions}

Students and teachers described the use of clickers as dynamic, motivating and participative. The majority of students and teacher were satisfied with the use of this technology and noticed improvements in learning dental pathology as a result of their use.

\section{References}

1. Norman G. Teaching basic science to optimize transfer. Med Teach. 2009;31:807-11.

2. Micheal J. Where's the evidence that active learning works?. Adv Physiol Educ. 2006;30:159-67.

3. Haden NK, Andrieu SC, Chadwick DG, Chmar JE, Cole JR, George $\mathrm{MC}$, et al. ADEA Commission on Change and Innovation in Dental Education. The dental education environment. J Dent Educ 2006;70:1265-70.

4. Henderson D, Sealover P, Sharrer V, Fusner S, Jones S, Sweet S, et al. Nursing EDGE: evaluating delegation guidelines in education. Int $\mathrm{J}$ Nurs Educ Scholarsh. 2006;3:1548-51.

5. Moredich C, Moore E. Engaging students through the use of classroom response systems. Nurs Educ. 2007;32:113-6.

6. Barber M, Njus D. Clicker evolution: seeking intelligent design. CBE Life Sci Educ. 2007;6:1-8.

7. Collins J. Audience response systems (ARS): technology to engage learners. J Am Coll Radiol. 2008;5:993-1000.

8. Smith DA, Rosenkoetter MM. Effectiveness, challenges, and perceptions of classroom participation systems. Nurse Educ. 2009;34:15661.

9. Collins LJ. Livening up the classroom: using audience response systems to promote active learning. Med Ref Serv Q. 2007;26:81-8.

10. FitzPatrick KA, Finn KE, Campisi J. Effect of personal response systems on student perception and academic performance in courses in a health sciences curriculum. Adv Physiol Educ. 2011;35:280-9.

11. Gauci SA, Dantas AM, Williams DA, Kemm RE. Promoting student-centered active learning in lectures with a personal response system. Adv Phys Educ. 2009;33:60-71.

12. Thomas CM, Monturo C, Conroy K. Experiences of faculty and students using an audience response system in the classroom. Comput Inform Nurs. 2011;29:396-400.

13. Holmes RG, Blalock JS, Parker MH, Haywood VB. Stu $\neg$ dent accuracy and evaluation of a computer-based audience response system. J Dent Educ. 2006;70:1355-61.

14. Satheesh KM, Saylor-Boles CD, Rapley JW, Liu Y, Gadbury-Amyot CC. Student evaluation of clickers in a combined dental and dental hygiene periodontology course. J Dent Educ. 2013;77:1321-9.

15. Wenz HJ, Zupanic M, Klosa K, Schneider B, Karsten G. Using an audience response system to improve learning success in practical skills training courses in dental studies - a randomised, controlled cross-over study. Eur J Dent Educ. 2014;18:147-53.

16. Elashvili A, Denehy GE, Dawson DV, Cunningham MA. Evaluation of an audience response system in a preclinical operative dentistry course. J Dent Educ. 2008;72:1296-1303.

17. Pileggi R, O'Neill PN. Team-based learning using an audience response system: an innovative method of teaching diagnosis to undergraduate dental students. J Dent Educ. 2008;72:1182-8.

18. Johnson JT. Creating learner-centered classrooms: use of an audience response system in pediatric dentistry education. J Dent Educ. 2005;69:378-81.

19. Turpin DL. Enhance learning with an audience response system. Am J Orthod Dentofacial Orthop. 2003;124:607.

20. Homme J, Asay G, Morgenstern B. Utilisation of an audience response system. Med Educ. 2004;38:575.

21. Cain J, Black EP, Rohr J. An audience response system strategy to improve student motivation, attention, and feedback. Am J Pharm Educ. 2009;73:1-7.

22. Johnson JT. Creating learner-centered classrooms: use of an audience response system in pediatric dentistry education. J Dent Educ. 2005;69:378-81.

23. Picciano A, Winter R, Ballan D, Birnberg B, Jacks M, Laing E. Resident acquisition of knowledge during a noontime conference series. Fam Med. 2003;35:418-22.

Acknowledgements

The authors thank the students and teachers of Dental Pathology, Operative Dentistry and Endodontics I (University of Valencia) for their participation in this study. 